\title{
Defining gut mycobiota for wild animals: a need for caution in assigning authentic resident fungal taxa
}

\author{
Anton Lavrinienko ${ }^{1}$, , Tiffany Scholier $^{1}$ (1), Scott T. Bates ${ }^{2}$, Andrew N. Miller ${ }^{3}$ and Phillip C. Watts ${ }^{*^{*}}$ (D)
}

\begin{abstract}
Animal gut mycobiota, the community of fungi that reside within the gastrointestinal tract, make an important contribution to host health. Accordingly, there is an emerging interest to quantify the gut mycobiota of wild animals. However, many studies of wild animal gut mycobiota do not distinguish between the fungi that likely can reside within animal gastrointestinal tracts from the fungal taxa that are non-residents, such as macrofungi, lichens or plant symbionts/pathogens that can be ingested as part of the host's diet. Confounding the non-resident and resident gut fungi may obscure attempts to identify processes associated with the authentic, resident gut mycobiota per se. To redress this problem, we propose some strategies to filter the taxa identified within an apparent gut mycobiota based on an assessment of host ecology and fungal traits. Consideration of the different sources and roles of fungi present within the gastrointestinal tract should facilitate a more precise understanding of the causes and consequences of variation in wild animal gut mycobiota composition.
\end{abstract}

Keywords: Amplicon sequencing, Community analysis, Host-microbe interaction, Intestinal fungi, Microbiota, Microfungi, Mycobiome

\section{Gut microbiota impact host health}

All animals host complex communities of commensal microbes (bacteria, fungi, protozoans, and viruses), the microbiota, which may comprise some hundreds to thousands of species [1-3]. Perhaps the most important, and certainly the most studied, component of host-associated microbiota are the communities of bacteria that inhabit the gastrointestinal tract (e.g. $[1,2,4])$. Numerous studies have identified diverse actions of gut bacteria that impact host health, for example provisioning of essential vitamins and metabolites by fermenting otherwise indigestible foodstuffs $[1,4]$, and helping to improve the host's

\footnotetext{
${ }^{*}$ Correspondence: phillip.c.watts@jyu.fi

1 Department of Biological and Environmental Science, University of Jyväskylä, 40014 Jyväskylä, Finland

Full list of author information is available at the end of the article
}

defence against pathogens through their dialogue with the host's immune system [5-7].

An important feature of the digestive tract is that, as an open system, it will contain material from ingested microbes that may be dead, inactive, or form temporary interactions with the resident gut microbiota. Presence of this allochthonous microbial material provides an opportunity to identify spurious associations between the 'apparent' gut microbiota and properties of the host and its environment, potentially obscuring attempts to identify the core, resident gut microbiota and its functions. The impact of microbial material originating from dietary intake is a problem for studies of the microbiota of the stomach and small intestine that host relatively few (compared with the colon) living bacterial cells [8]. By contrast, as the human colon microbiota contains some $10^{10}-10^{11}$ resident bacteria, the estimated relative abundance of ingested bacteria compared with the resident original author(s) and the source, provide a link to the Creative Commons licence, and indicate if changes were made. The images or other third party material in this article are included in the article's Creative Commons licence, unless indicated otherwise in a credit line to the material. If material is not included in the article's Creative Commons licence and your intended use is not permitted by statutory regulation or exceeds the permitted use, you will need to obtain permission directly from the copyright holder. To view a copy of this licence, visit http://creativecommons.org/licenses/by/4.0/. 
gut flora is some 0.0001-0.00001 fold [8]. Indeed, an analysis of the gut microbiota in human samples traced some bacteria to host diet, but the numbers of suspected dietary-associated material was low (towards the limit of detection) [2]. The direct contribution of dietary material to the apparent composition of gut bacteria is rarely examined, possibly because the hostile environment of the (vertebrate) stomach [9] is expected to kill many ingested microbes such that the composition of the gut microbiota should reflect the dynamics of the authentic resident bacteria. While it could be interesting to quantify the potential for ingested bacteria to pass alive through an animal's digestive system in a greater diversity of host taxa, here we emphasise the general need to routinely assess the likely resident status of the gut fungal community, especially in studies of wild animals. The principal reasons to adopt this as standard practice for analyses of wild animal gut mycobiota are: (1) substantially fewer fungal cells reside within the animal gut than bacteria [10] and (2) many animals consume fungi. The outcome is an enhanced opportunity for a substantially reduced signal to noise ratio (i.e. a greater contribution of allochthonous material) in analyses of the gut mycobiota compared with analyses of gut bacteria.

\section{Gut mycobiota as an important but neglected component of animal microbiota}

Although less well studied than the gut bacteria [10], there is increasing recognition that the gut mycobiota, the community of fungi that reside in gastrointestinal tracts, make an important contribution to host health [10-17]. Following such studies on humans and laboratory animals, there is emerging interest to establish the processes that determine the composition of the gut mycobiota of wild animals. For instance, host diet is associated with variation in the bat [18] and butterfly [19] gut mycobiota. Also, gut mycobiota of wild primates were species-specific and associated with habitat type, and possibly variation in diet [20].

An apparent feature of the gut microbiota is that there are orders of magnitude fewer fungal cells than bacterial cells in an animal gut microbiota. Estimates of total fungal load vary from 5 to $7 \%$ in laboratory mice faeces [21] to a perhaps more typical fraction of about $0.1 \%$ of the gut microbiota $[1,10]$. The reduced abundance of fungal cells makes analyses of the gut mycobiota sensitive to the material from ingested fungi. For example, David et al's [2] analysis of the human gut microbiota identified an increase in the proportion of one food borne fungus (Penicillium) that apparently reduced the relative proportions of other fungi. The awareness that many humans regularly consume fungi as part of their diet, highlight the need to separate the resident gut mycobiota, which actively participates in host-microbiota interactions, from the transient 'passengers' who passively travel through the host's gastrointestinal tract [14, 22, 23]. A meta-analysis of human gut mycobiota identified rather few fungal taxa (e.g. yeasts assigned to Candida, Saccharomyces and/or the Dipodascaceae, and Malassezia species) common to most studies, with many fungal taxa reported only once [24]. One interpretation of these data is that potentially many fungi identified in the human gut mycobiota studies are incapable of long-term residence in the gastrointestinal tract $[22,24]$. In many instances, differentiation between the resident and ingested components of the gut mycobiota is aided in studies of human (and laboratory animal) microbiota where it is frequently possible to, for example, obtain detailed information about host lifestyle (e.g. diet), readily collect longitudinal data, and/or benefit from a large, collective research effort that is devoted to validating fungal species' ability to reside within the gut (e.g. using culturing and experimentation). By contrast, studies of wild animal gut mycobiota are often based solely on the inference from an amplicon sequencing-based survey of a limited number of samples.

\section{Amplicon sequencing is an 'unselective' tool for analysis of gut mycobiota}

One of the advances and drawbacks in analyses of microbial communities is the increasing use of high-throughput amplicon sequencing, also known as marker gene analysis [25] or metabarcoding [15, 26]. High-throughput amplicon sequencing relies on PCR to amplify a target region of DNA, which is typically part of the ribosomal RNA locus [15, 27], generating thousands to millions of sequence reads from samples containing DNA from diverse sources [15, 28]. Amplicons are compared against a reference database (e.g. [29]) to assign taxonomic identities to generated sequence variant (SV) groups (also known as operational taxonomic units (OTUs), phylotypes (PTs), etc.). Counts of the number of reads from each SV group can be further used to estimate the relative abundance of SVs $[15,30,31]$. High-throughput amplicon sequencing has revolutionised analyses of microbial communities by circumventing the need to isolate and culture microbes, a task that can be challenging and time consuming [16]. With the development of standardized protocols ([25]; https://earthmicrobiome. org/), extensive reference databases [29], and bioinformatics pipelines [15, 32], it is quite straightforward to use high-throughput amplicon sequencing to characterize microbial communities from diverse environments. A disadvantage associated with bypassing a culturing step to isolate and identify microbial species is that it can be hard to validate whether or not nominal species could 
reside within the environment from which their DNAs were recovered. Many analyses of host-associated gut mycobiota in wildlife overlook the issue that amplicon sequencing will amplify all fungal DNA present within a sample from an animal's gut or faeces and the method does not distinguish between authentic resident gut fungi and other non-resident fungi.

\section{Separating the wheat from the chaff: non-resident fungi are present in analyses of wild animal 'gut mycobiota'}

Animal gastrointestinal tracts may contain non-resident fungal material via diverse routes (Fig. 1), such as by active consumption or by incidentally ingesting commensal/symbiotic, pathogenic, coprophilous or other saprotrophic species (of fungi or spores) with their diet. Macroscopic fungi, lichens, and/or fungal plant pathogens or commensal fungi (for example ectomycorrhizal species) are likely components of the host diet rather than authentic, resident gut mycobiota. Numerous examples of inclusion of potential non-resident fungi in surveys of 'gut mycobiota' exist in the literature. For example, a study of two species of primates identified microfungal taxa in the Saccharomycetales to be dominant components of the primate gut mycobiota [20], but nonetheless reported some SV groups that were assigned to macrofungi (e.g. Polyporales, Agaricales) that include bracket-fungi and mushrooms, as well as some plant pathogens (e.g. members of Pestalotiopsis and Lasiodiplodia). Similarly, gut mycobiota in two species of wild mice were dominated by yeasts assigned to the genus Kazachstania, but contained SV groups assigned to a polypore, Trametes versicolor [33]. Further, SV groups assigned to macrofungi (Steccherinaceae and Strophariaceae, which include polyporoid and mushroom-forming species, respectively) form an abundant component of the apparent gut mycobiota of small rodents [34]. Indeed, SV groups assigned to macrofungi and plant pathogens or endophytes occur in analyses of gut mycobiota of diverse wild animal taxa, including macaques [35], bats [18], zebrafish [36], and birds [33, 37].

An appraisal of the likely resident or non-resident status of the SV groups present in a wild animal gut mycobiota is essential for a precise interpretation of how the gut fungal community composition may respond to environmental heterogeneity. For example, one response of the fungal community in fecal samples from yellow-necked mice inhabiting ecosystems that had experienced different levels of burning was a change in abundance of Gelatoporia sp. [34]. Since Gelatoporia is a genus of poroid crust fungi producing white rot that inhabits dead wood [38], these data may reflect the condition of the host's environment and diet rather than an effect of environment on the resident gut mycobiota per se. More generally, it is relevant that the number of SV groups reported by studies of wild animal gut mycobiota varies considerably [20,33, 39]. As the taxonomic diversity of an apparent 'gut mycobiota' can be inflated by the presence of fungal SVs from the host's diet (Fig. 1 and Box 1), it is not possible to determine whether this variation in diversity reflects interspecific differences in the authentic, resident gut mycobiota or not. Inclusion of non-resident fungi in amplicon sequence data can interfere with producing reliable estimates of gut mycobiota alpha and beta diversity metrics, in an unpredictable manner due to the opportunistic nature of ingesting non-resident fungi (Fig. 1, see also Box 1).

\section{Box 1}

To illustrate the potential effect of filtering of sequence variant (SV) groups assigned to wild animal gut mycobiota we examined the data in Antwis et al. [34]. This study characterised the gut mycobiota of four species of rodent (bank vole, Myodes glareolus $n=152$, wood mouse, Apodemus sylvaticus $n=24$, striped field mouse, $A$. agrarius $n=25$, and yellow-necked mouse, A. flavicollis $n=54)$ inhabiting the Chernobyl Exclusion Zone, Ukraine. Antwis et al. (2021) reported interspecific differences in the gut mycobiota community and some evidence that the proportion of two families of fungi associated with the host's exposure to radionuclides. Briefly, read data were obtained from Genbank (accession number: PRJNA594002) and processed in QIIME2 v.2020.6 [32], using the CUTADAPT [60] and DADA2 [61] plugins to remove adapters and denoise the data. Taxonomy was assigned using VSEARCH [62] against the UNITE v.8 reference database [29]. To identify and filter likely non-resident SV groups (e.g. macrofungi, lichens) we classified fungal taxa based on their guild or growth forms using FUNGUILD v.1.2 [54], and also assigned broad categories of fungi as microfungi (or not) based on the information provided in the microfungi database (https://www. microfungi.org/Table1). Data were imported in R and merged into a PHYLOSEQ [63] object for analyses of alpha (SVs richness) and beta (Bray-Curtis dissimilarity) diversity. The adonis 2 function in $\mathrm{R}$ package VEGAN [64] was used to examine whether host species identity (e.g. bank vole, wood mouse, striped field mouse, yellow-necked mouse), sampling year (2017, 2018) and/or total absorbed dose rates of radiation $(\mu \mathrm{Gy} / \mathrm{hr})$ explained variation in beta diversity. As a general assumption, we make a contrast between SVs representing potential dietary items (e.g. macrofungi, lichens) and against the remaining microfungal data (e.g. microfungi, yeasts, animal symbionts), but excluding those with an obvious relationship 


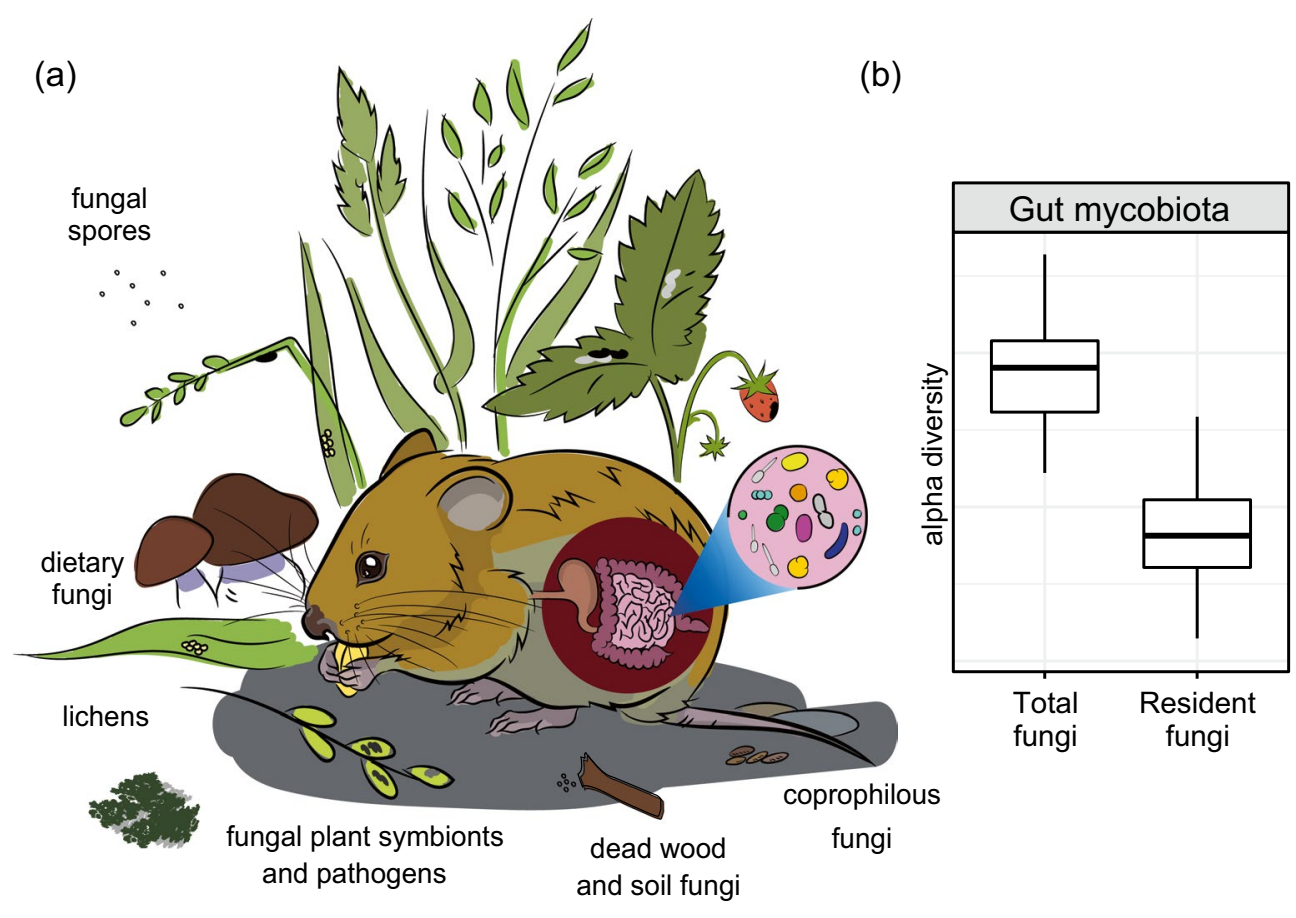

(c)

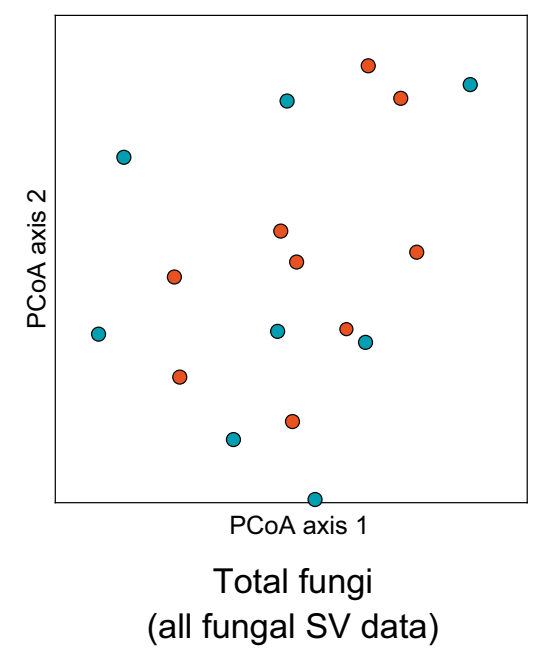

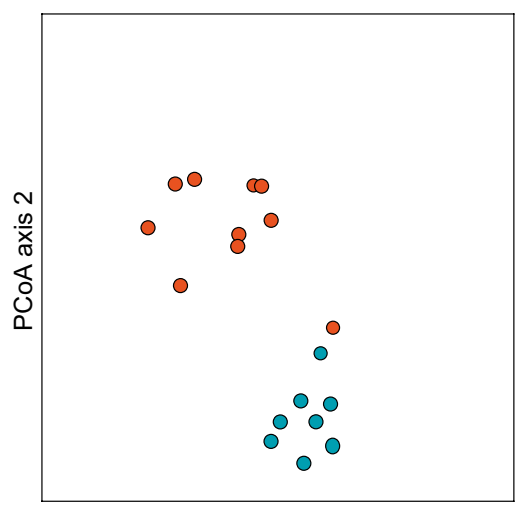

PCoA axis 1

Resident fungi

(filtered SV data)

Fig. 1 Potential sources of non-resident fungi in the gut mycobiota associated with wild animals. a Intake of non-resident fungi into an animal's gastrointestinal tract can occur via active consumption, for example of dietary fungi or lichens, or via passive ingestion, for example of plant symbionts/pathogens, fungal spores from the environment, and/or by incidental ingestion of soil particles. $\mathbf{b}$ While inclusion of incidental fungi will elevate measures of alpha diversity, $\mathbf{c}$ the effect of inclusion of non-resident fungal sequence variant (SV) groups in analyses of beta diversity is unclear. In this hypothetical beta diversity analysis (e.g. principle coordinates analysis, PCoA) each point represents a single sample. Samples are coloured according to the host species (e.g. 'orange' and 'blue'). Sample clustering pattern in the gut mycobiota associated with 'orange' and 'blue' hosts can be driven by a combination of the amount of environmental material ingested by the host and/or by variation in environmental fungal communities. Differences in sample grouping between the two ordinations illustrate the potential difficulties associated with inferring the likely causes of variation in wildlife gut mycobiota without identifying and filtering non-resident gut fungi

with plants (e.g. ectomycorrhizae, plant pathogens). For analyses, the data were rarefied to an even depth of 1500 (all data, and the filtered microfungi) or 500 (likely non-resident fungal SVs) reads per sample.
When considering all fungal SV data, these rodents apparently harbour a relatively diverse gut mycobiota with an average of 50-90 SVs per host species (Box Fig. 1a). Partitioning the data into likely resident and 
Table 1 Experimental design considerations and their relevance in studies of wild animal gut mycobiota. The table describes potential resources and strategies to identify and filter non-resident gut mycobiota in amplicon sequence data

\begin{tabular}{|c|c|c|}
\hline Category & What features are important? & Why are these metadata important? \\
\hline \multirow[t]{4}{*}{ 1. Metadata } & Host diet & $\begin{array}{l}\text { Host diet determines the likely amount of fungal contamination, e.g. omnivores should ingest } \\
\text { more dietary fungi than carnivores }\end{array}$ \\
\hline & Niche specialisation & $\begin{array}{l}\text { Dietary specialisation determines the potential diversity of fungal contamination, e.g. general- } \\
\text { ists may ingest a higher diversity of environmental fungi than specialists }\end{array}$ \\
\hline & Developmental stage & $\begin{array}{l}\text { Host diet may change during development, e.g. adult mammals have a higher likelihood of } \\
\text { ingesting fungi than neonates (that consume milk) }\end{array}$ \\
\hline & Season & Both host diet and the type and availability of fungi can change with season \\
\hline \multirow[t]{7}{*}{ 2. Sampling scheme } & Longitudinal sampling & $\begin{array}{l}\text { A time series analysis of the gut mycobiota can be used to define a set of core fungal sequence } \\
\text { variant (SV) groups (especially in animals whose dietary fungi are seasonally available) }\end{array}$ \\
\hline & Spatial sampling & $\begin{array}{l}\text { Increasing the spatial extent of sampling can help to identify the core fungal SVs based on } \\
\text { frequency of occurrence }\end{array}$ \\
\hline & Time that sample is exposed to the environment & $\begin{array}{l}\text { Fungi may rapidly colonise and grow on faeces after defecation (a more prominent risk for } \\
\text { non-invasive sampling) }\end{array}$ \\
\hline & Time since sample collection & $\begin{array}{l}\text { Time between sample collection and preservation determines the potential for overgrowth of } \\
\text { certain fungi }\end{array}$ \\
\hline & Source tracking & $\begin{array}{l}\text { Information about fungi that inhabit the host's environment and/or diet can be used to iden- } \\
\text { tify the taxa that have the potential to be commonly ingested }\end{array}$ \\
\hline & Negative/positive controls & A diverse community of microbes can be present within the laboratory and the reagents, \\
\hline & Sterile work & $\begin{array}{l}\text { and contamination of samples by these microbes should be avoided as much as possible to } \\
\text { maximise the signal to noise ratio in the data }\end{array}$ \\
\hline \multirow[t]{3}{*}{$\begin{array}{l}\text { 3. Bioinformatic } \\
\text { analyses }\end{array}$} & $\begin{array}{l}\text { Positive filter using reference database(s), e.g. } \\
\text { Targeted Host Fungi database }\end{array}$ & $\begin{array}{l}\text { Fungal SVs that reside in the digestive systems of other animals are likely also to inhabit wild } \\
\text { animal's gut. Note that reference databases are not always correct or up to date. The author(s) } \\
\text { must clearly state the version of a database used in their analyses }\end{array}$ \\
\hline & $\begin{array}{l}\text { Filter SVs using fungal traits database(s), e.g. } \\
\text { FUNGuild }\end{array}$ & $\begin{array}{l}\text { Fungal SVs that have certain traits or growth forms, e.g. being 'macrofungi', are unlikely to be } \\
\text { authentic residents of the gut microbiota }\end{array}$ \\
\hline & Comparative analysis & $\begin{array}{l}\text { Captive and/or laboratory animals often have less opportunities to ingest a diverse community } \\
\text { of fungi, and these data may allow the likely ingested fungal SVs to be identified in wild } \\
\text { conspecifics }\end{array}$ \\
\hline
\end{tabular}

non-resident SVs results in a two-fold reduction of the estimates of the gut mycobiota diversity (Box Fig. 1a). Similarly, the variation in the gut mycobiota beta diversity between host species depends on the types of fungal SVs included (Box Fig. 1b). Indeed, there is somewhat clearer separation of the samples from bank voles and the three mouse species when all fungal SVs are included in the analysis compared with the analysis of only the probable resident gut fungi. Also, samples of wood mice tend to cluster with bank voles and differ from the samples of striped field and yellownecked mouse when analysing likely non-resident fungal SVs. Moreover, filtering the data indicates that the strength of association between gut mycobiota and radiation dose rate can be affected by the types of fungal SVs included ( $c f . R^{2}$ and $p$-values in Box Table 1) and thus can influence the study conclusions. Hence, the data presented in Antwis et al. (2021) likely require careful filtering and re-analyses to make robust inferences about the possible ecological drivers of gut mycobiota variation. These data demonstrate a clear need for caution when analysing wildlife gut mycobiota communities characterised using amplicon sequence data alone.

\section{Strategies to identify non-resident and resident gut mycobiota SV groups}

While classification of fungal taxa as likely residents and non-residents of the gut mycobiota is key for understanding processes that shape wild animal gut mycobiota communities, many studies of wildlife microbiota will lack the time and resources to make the necessary culturing experiments to confirm whether suspected members of the gut mycobiota could actually reside within the host's digestive system. With this in mind, three broad strategies can be adopted to more accurately identify the likely causes and consequences of variation in wildlife gut mycobiota: (1) provide explicit data on host ecology, (2) improve experimental design and sampling, and (3) employ bioinformatic-based filtering of SVs (Table 1).

Host ecology and life stage play an important role in determining the expected proportion of non-resident fungi within the gut (Table 1). Many animals actively ingest fungi as part of their diet. For instance, omnivorous or herbivorous hosts are expected to ingest more non-resident fungi than insectivorous or carnivorous hosts (e.g. a comparison between phytophagous vs. insectivorous bats; [18]). While the timing and amount of fungi ingested is poorly documented for many species 


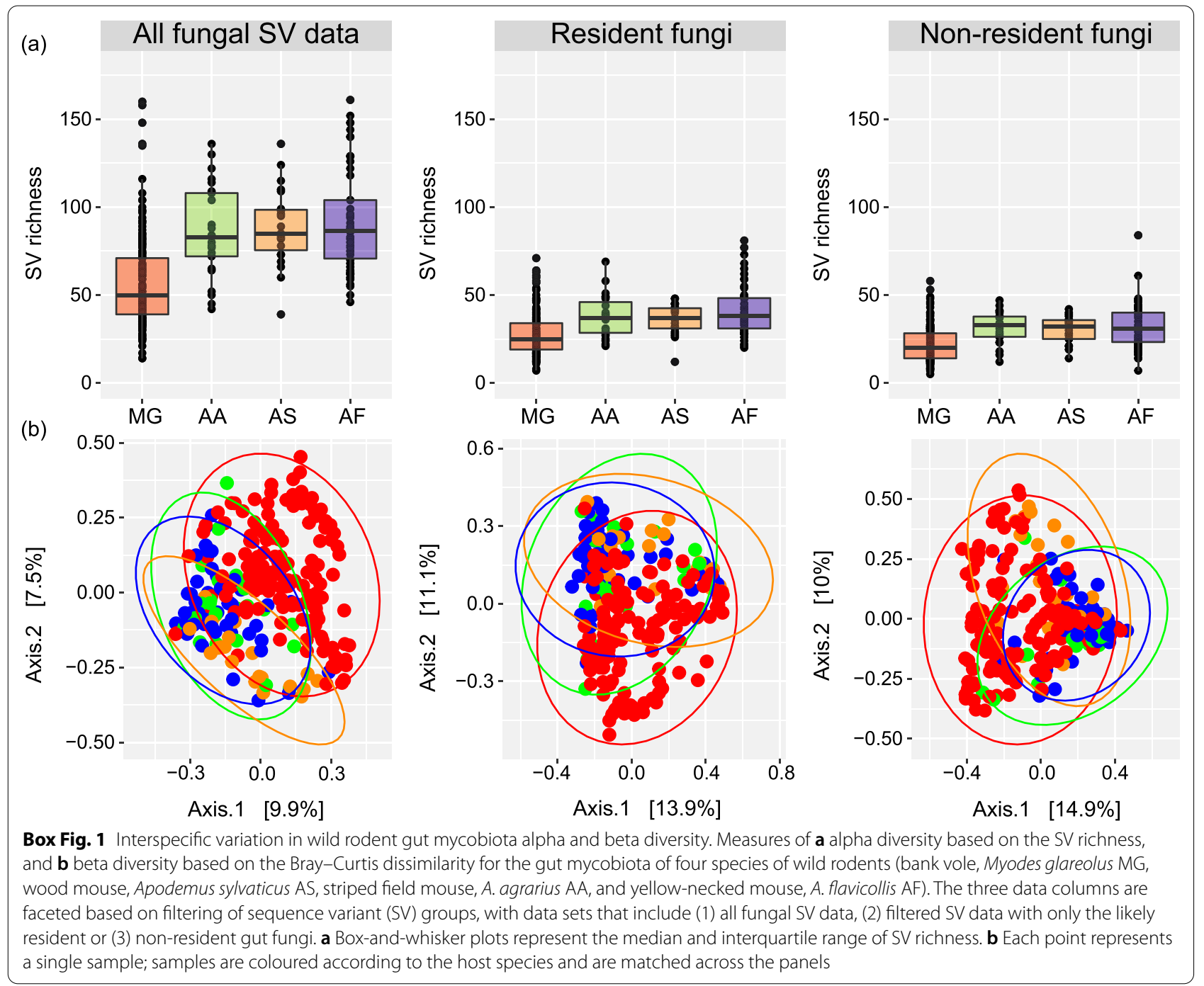

there is some evidence that active consumption of fungi by apparent herbivores could be quite common [40]. Greater diversity of non-resident fungi may be expected in samples from dietary generalists than dietary specialists. Indeed, analyses of gut mycobiota in butterflies [19], zebrafish [36], and captive tigers [41], have not uncovered SV groups belonging to obvious macrofungi or lichens, which is expected given the diets of these animal taxa. Nonetheless, these three studies have assigned SV groups to fungi inhabiting soil, or those that are plant pathogens or endophytes, whose membership in the resident gut mycobiota is unclear. Interestingly, the gut mycobiota of omnivorous yellow baboons was less diverse than that of the leaf-eating specialist red colobus, which were characterised by high levels of inter-individual variation with only few fungal SV groups shared among red colobus individuals [20]. As an example of ontogenetic shifts in gut mycobiota, humans experience a large reorganization of their gut mycobiota during the first year of life that accompanies the transition to solid food [16]. While there are no data on gut mycobiota establishment in early life for wild mammals, post-weaning individuals can be expected to ingest more non-resident fungi than neonatal individuals feeding on milk, thus host life stage can affect the intake of non-resident fungi into an animal's gut and caution is needed. Thus, studies of gut mycobiota should include an explicit statement about the likely sources of ingested fungi, whether direct (e.g. macrofungi, lichens) or indirect (e.g. plant pathogens, symbionts or commensals), that would be detected quite readily by amplicon sequencing.

General guidelines to promote best practices in sampling, laboratory procedures and data analyses in studies of microbiota [25], and specifically mycobiota [15], have been presented elsewhere, and are not discussed in detail here-rather we highlight the need to further consider 
Box Table 1 Statistical tests on the Bray-Curtis dissimilarity for the gut mycobiota of four species of wild rodents (bank vole, Myodes glareolus, wood mouse, Apodemus sylvaticus, striped field mouse, A. agrarius, and yellow-necked mouse, A. flavicollis). Statistical tests were performed using the adonis2 function in R package VEGAN to (1) examine whether host species, sampling year and/or total absorbed dose rates of radiation ( $\mu \mathrm{Gy} / \mathrm{h}$ ) explained variation in beta diversity when all fungal sequence variant (SV) groups are included in the analysis, and (2) to compare explained variation with the analyses based on filtered SV data that either include only the likely resident or non-resident gut fungi

\begin{tabular}{|c|c|c|c|c|c|c|c|c|c|}
\hline & All & data & & & & & No & t fung & \\
\hline & $D f$ & $R^{2}$ & $p$ & $d f$ & $R^{2}$ & $p$ & $d f$ & $R^{2}$ & $p$ \\
\hline Host & 3 & 0.028 & 0.001 & 3 & 0.029 & 0.001 & 3 & 0.031 & 0.001 \\
\hline Dose & 1 & 0.007 & 0.005 & 1 & 0.006 & 0.045 & 1 & 0.007 & 0.032 \\
\hline Year & 1 & 0.019 & 0.001 & 1 & 0.021 & 0.001 & 1 & 0.016 & 0.001 \\
\hline
\end{tabular}

the ecologies of the hosts and fungi after implementing the best practice study design and analysis. Nonetheless, a robust analysis of the gut mycobiota of wildlife requires careful experimental design to focus the analysis on the authentic resident fungal taxa (Table 1). During the sampling step, collection of fresh fecal material is important to minimise the number of reads assigned to, for example, non-resident coprophilous fungi. Instant freezing will further decrease the chance of germination of any fungal spores present or overgrowth by moulds [15], more faithfully preserving the gut mycobiota community composition. Reagent and laboratory contamination can also impact analyses of gut mycobiota [42, 43]. Therefore, the use of negative controls (e.g. sample blanks) and/or positive controls with a mock community of known composition during DNA extraction, PCR and sequencing steps can help to detect potential contamination [15]. Working under a sterile laminar hood further decreases the risk of contamination with fungal spores from the built environment. In addition to these general guidelines, an important best practice to be adopted in analyses of gut mycobiota will be an assessment of the database of SVs to identify the taxa that, due to reasons described above, are unlikely to be resident members of the gut mycobiota.

Other sampling strategies to help identify the resident component of the gut mycobiota include source tracking [44] or making a time series analysis of the gut mycobiota composition (Table 1). Source tracking to identify the potential environmental source(s) of components of the host gut mycobiota could provide many insights into the processes that determine gut mycobiota community assembly and help identify the 'gut specialist' fungi; for example, butterfly [19] and caterpillar [45] gut mycobiota differ from the fungal communities associated with their potential food. Meaningful source tracking requires data from appropriate sources, such as those associated with potential diet and other appropriate features of host's habitat, and obtaining these samples may be problematic (e.g. unknown diet, cryptic habitat use, etc.) and/or too resource intensive to acquire. Even with these challenges, it is possible to query one's own or public (e.g. [46, 47]) data on environmental (e.g. soil, plant-associated) fungal communities to obtain some insight into the main groups of fungi that reside outside animal gastrointestinal tracts but within the host's general living environment. We stress that this strategy would have to be applied with caution as some apparent environmental fungi could be transient themselves, for example incidentally introduced via animal faeces. Longitudinal sampling could be used to identify the stable (and likely resident) gut mycobiota, applying concepts of the common and temporal core mycobiota (e.g. taxa that occur in most individuals or sampling events within a defined host population or species) $[48,49]$. Sampling humans at several time points revealed an apparently unstable gut mycobiota $[22,50,51]$ with rather few fungal taxa detected across multiple samples due to the suspected presence of nonresident fungi. Longitudinal studies could also be useful to elucidate the effects of variation in diet and habitat use (Table 1). For instance, by sampling different seasons one could identify changes in the frequency of fungal fruiting bodies or plants (and associated fungal taxa) that constitute part of the host's diet. Another method to identify the core gut mycobiota in a species of interest, is to compare fungal SV groups between wild and captive individuals, as wild animals are expected to ingest more non-resident fungi compared to their captive counterparts [36]. Collecting samples from diverse habitats can also help to define the core mycobiota (e.g. by applying frequency-based filtering) and thus reduce uncertainty when assigning authentic resident fungal taxa. Some caution would still need to be applied with any frequencybased filtering, as regular ingestion of plant-associated fungi (e.g. pathogens, symbionts or commensals) could identify certain fungal taxa as a 'core species' even if they cannot reside within the animal gut.

Bioinformatic-based filtering can be used to focus the analyses on the authentic resident gut mycobiota. This 
strategy may be the only reasonable option when the sampling strategies mentioned above are not practical, for example because of a lack of information about host ecology or because it is not possible to obtain longitudinal samples. Some studies of gut mycobiota have filtered SV groups using a database, such as the Targeted Host Fungi database (THF; [52]); https://risccweb.csmc.edu/micro biome/thf/), as a positive filter of resident gut fungi [53]. However, even this manually curated reference database, which is optimized for annotation of gastrointestinal fungi of laboratory animals and humans, contains examples of likely non-resident macrofungi species, including Agaricus bisporus (a cultivated variety of the champignon mushroom) and Boletellus projectellus (a wild bolete fungus) (see THF v1.6.1, date accessed: January 15, 2021; [52]). As yet, there is no comparable database of fungi that are confirmed resident members of wild animal gastrointestinal tracts. Nonetheless, separating fungal SV groups into broad categories, such as microfungi, lichens, or macrofungi, is a useful first step as the latter two groups are very likely to be non-resident fungi. Although there is no universally accepted definition of macro- and microfungi, the Microfungal Collections Consortium (https://www.microfungi.org/Table1) summarizes known classes of microfungi. The software FUNGuild ([54]; http://funguild.org) provides an additional resource to identify and filter non-resident SV groups, for example, by classifying fungi as lichens (i.e. Guild=Lichenized) or by macrofungal morphological types (e.g. Growth Form $=$ Agaricoid, Gasteroid, Polyporoid, Secotioid, etc.). Other databases for assigning functional traits and ecological information to fungal SVs include $\mathrm{FUN}^{\mathrm{FUN}}$ [55] and FungalTraits [56]. While lichens and macrofungi perhaps represent reasonable lifestyles to categorize as non-residents of the animal gut, identifying the authentic resident gut microfungi will be challenging. Non-resident gut microfungi will likely reflect the dietary habits of the host and, for example, could include fungal taxa that are plant pathogens and plant symbionts (e.g. Guild = Plant Pathogen or Endophyte, respectively). To further complicate matters, some fungi are not easily defined ecologically [55]. Nonetheless, as an example, Ravenscraft et al. [19] conducted extensive filtering of fungal SVs based on fungal ecology and removed fungal SV groups assigned to wood decomposers and ectomycorrhizal, arbuscular, or ericoid mycorrhizal guilds from their butterfly gut mycobiota data. Using one or more of the databases of fungal traits, large amounts of SV data can be filtered as likely resident or non resident in the animal gut. It is important to emphasise the need for transparency and reproducibility when adopting this procedure, and thus the author(s) must clearly state the filtering steps used in their analyses and should provide (1) a comparison between the filtered data and all data (e.g. as supplemental information) and (2) accompanying metadata that lists (2.i) each SV and (2.ii) its assigned taxonomy, (2.iii) each SV's guild (assigned by a defined version of a fungal traits database), and (2.iv) the resident/non-resident status assigned by the author(s).

\section{Don't 'throw the baby out with the bathwater': need for caution when filtering fungal SV data}

Although we advocate that informed filtering of the fungal SVs identified in a gut or faecal sample is required to better characterise the likely resident gut mycobiota of wild animals, we stress that the filtering process yields an informed 'hypothesis' about some aspect of the wild animal gut mycobiota. In most studies there will be a need to further consider possible roles of the different classes of SVs that exist within the data. For example, ingested probiotic bacteria may elicit functional changes in the gut microbiota even if the probiotic bacteria have little detectable impact on the microbiota community per se [57]. Focusing an analysis only on the suspected resident gut mycobiota could also overlook the possible functions that transient fungal SVs could perform during their passage through the host's gastrointestinal tract. Moreover, an uncritical removal of fungal SVs based on their traits could hinder the identification of novel taxa involved in authentic fungal-animal relationships. For instance, SVs assigned to 'cyanobacteria' have been previously identified in samples of animal microbiota. At first glance, such data were often thought to represent non-resident bacteria, possibly as a contaminant fraction, as photosynthetic cyanobacteria should not reside in animal gastrointestinal tracts. However, subsequent metagenomic analyses uncovered the genomes of a novel phylum, Melainabacteria, an apparent sibling phyla to the Cyanobacteria that can perform potentially useful metabolic services for its animal host [58]. In this case, dismissing SVs based on putative traits could have resulted in overlooking this novel and unique phylum of resident-microbiota. With this in mind, the value of maintaining explicit metadata about the putative association of each SV with its host (e.g. resident, dietary, core, temporary) would provide a valuable resource to stimulate discussion and to better enable other researchers to collate datasets and examine the occurrence of SVs associated with hypothesised resident, transient, dietary, etc. status within wildlife gut mycobiota.

\section{Concluding remarks}

Quantifying the diversity and function of the gut mycobiota is likely to provide a better understanding of processes that affect health and fitness in wild animals. Frequent occurrence of dietary material and/or notable plant symbionts and plant pathogens in wild animal gut 
mycobiota communities highlights the need for clarity about the definition of an authentic gut mycobiota as identified in typical high-throughput amplicon sequencing surveys. While best practices for technically sound microbiota/mycobiota analyses are covered elsewhere $[15,25]$, there is a clear need to consider more deeply the life history and ecology of the Fungi when analysing gut mycobiota of wildlife. Hence, here we propose a checklist to accompany analyses of wild animal gut mycobiota, specifically focusing on the strategies and available resources to identify and filter non-resident gut mycobiota (Table 1). Before data on wild animal gut mycobiota accumulate, it is essential that studies include an explicit step of 'informed filtering' about which SVs reflect the resident and non-resident components of the gut mycobiota. It would be helpful to adopt a standard practice whereby each manuscript is accompanied by metadata that contains an annotated list of fungal SV groups, their abundance, prevalence among examined individuals, putative classifications (e.g. as macrofungi, microfungi or lichens, mushrooms, polypores, etc.), and representative sequences. Such metadata should be deposited as standard supplementary information and would facilitate meaningful re-use of data and meta-analyses. Without a reasonable attempt to understand the sources and ecology of fungal SV groups identified from animal gut/ fecal samples, analyses of the diversity and function of wild animal 'gut mycobiota' could be compromised (Box 1). While fungi have diverse life histories and ecologies, which are poorly characterized for many species, it is still better to adopt some informed filtering for SV groups that likely do not reside in the animal gut than to overlook this issue. Moreover, recognizing the diversity of fungal SV groups that can be retrieved from gut and fecal samples of wild animals may provide new research opportunities such as using animals as 'natural samplers' of environmental fungal diversity or to track fungal pathogens [59]. While there are many opportunities to identify the interactions between wild animals and their associated fungal communities, there is a current critical need for more consideration of what constitutes resident versus non-resident gut mycobiota.

\section{Acknowledgements}

We are grateful for the thoughtful comments from three referees and the editor that improved the manuscript. We would also like to thank the Finnish Centre for Scientific Computing (CSC) for computing resources.

\section{Authors' contributions}

Article was conceived by PCW, STB, ANM and AL and drafted by PCW, AL and $\mathrm{TS}$, with all authors contributing to the final version.

\section{Funding}

We are grateful for funding from the Academy of Finland (287153, 329334, 324602) to P.C. Watts, and funding from the University of Jyväskylä to support T. Scholier. Research support was provided to S.T. Bates through the Nils K.
Nelson Endowment in the College of Engineering and Sciences at Purdue University Northwest.

\section{Availability of data and materials}

The raw sequence data originally presented in the study by Antwis et al. 2021 (https://doi.org/10.1111/1365-2656.13507) are available from the NCBI SRA database under accession number PRJNA594002. All the other data generated or analysed during this study are included in this published article (and its supplementary information files).

\section{Declarations}

Ethics approval and consent to participate

Not applicable.

Consent for publication

Not applicable.

\section{Competing interests}

The authors declare that they have no competing interests.

\section{Author details}

${ }^{1}$ Department of Biological and Environmental Science, University of Jyväskylä, 40014 Jyväskylä, Finland. ${ }^{2}$ Department of Biological Sciences, Purdue University Northwest, Westville, IN 46391, USA. ${ }^{3}$ University of Illinois UrbanaChampaign, Illinois Natural History Survey, 1816 South Oak Street, Champaign, IL 61820-6970, USA.

Received: 14 April 2021 Accepted: 27 September 2021

Published online: 28 October 2021

\section{References}

1. Qin J, Li R, Raes J, Arumugam M, Burgdorf KS, Manichanh C, et al. A human gut microbial gene catalogue established by metagenomic sequencing. Nature. 2010;464:59-65. https://doi.org/10.1038/natur e08821.

2. David LA, Maurice CF, Carmody RN, Gootenberg DB, Button JE, Wolfe BE, et al. Diet rapidly and reproducibly alters the human gut microbiome. Nature. 2014;505:559-63. https://doi.org/10.1038/nature12820.

3. Hird SM. Evolutionary biology needs wild microbiomes. Front Microbiol. 2017:8:725. https://doi.org/10.3389/fmicb.2017.00725.

4. Clemente JC, Ursell LK, Parfrey LW, Knight R. The impact of the gut microbiota on human health: an integrative view. Cell. 2012;148:1258-70. https://doi.org/10.1016/J.CELL.2012.01.035.

5. Hooper LV, Littman DR, Macpherson AJ. Interactions between the microbiota and the immune system. Science (80). 2012;336:1268-73. https:// doi.org/10.1126/SCIENCE.1223490.

6. Bäumler AJ, Sperandio V. Interactions between the microbiota and pathogenic bacteria in the gut. Nat. 2016;535:85-93. https://doi.org/10. 1038/nature18849.

7. Zipperer A, Konnerth MC, Laux C, Berscheid A, Janek D, Weidenmaier C, et al. Human commensals producing a novel antibiotic impair pathogen colonization. Nature. 2016:535:511-6. https://doi.org/10.1038/natur e18634.

8. Derrien M, van Hylckama Vlieg JET. Fate, activity, and impact of ingested bacteria within the human gut microbiota. Trends Microbiol. 2015;23:354-66. https://doi.org/10.1016/j.tim.2015.03.002.

9. Beasley DE, Koltz AM, Lambert JE, Fierer N, Dunn RR. The evolution of stomach acidity and its relevance to the human microbiome. PLOS ONE. 2015;10: e0134116. https://doi.org/10.1371/JOURNAL.PONE.0134116.

10. Huffnagle GB, Noverr MC. The emerging world of the fungal microbiome. Trends Microbiol. 2013;21:334-41. https://doi.org/10.1016/j.tim.2013.04. 002.

11. Wheeler ML, Limon JJ, Bar AS, Leal CA, Gargus M, Tang J, et al. Immunological consequences of intestinal fungal dysbiosis. Cell Host Microbe. 2016:19:865-73. https://doi.org/10.1016/j.chom.2016.05.003.

12. Chiaro TR, Soto R, Stephens WZ, Kubinak JL, Petersen C, Gogokhia L, et al. A member of the gut mycobiota modulates host purine metabolism 
exacerbating colitis in mice. Sci Transl Med. 2017. https://doi.org/10.1126/ scitransImed.aaf9044.

13. Huseyin CE, O'Toole PW, Cotter PD, Scanlan PD. Forgotten fungi-the gut mycobiome in human health and disease. FEMS Microbiol Rev. 2017:41:479-511. https://doi.org/10.1093/femsre/fuw047.

14. Lai GC, Tan TG, Pavelka N. The mammalian mycobiome: a complex system in a dynamic relationship with the host. Wiley Interdiscip Rev Syst Biol Med. 2018. https://doi.org/10.1002/wsbm.1438.

15. Nilsson RH, Anslan S, Bahram M, Wurzbacher C, Baldrian P, Tedersoo L. Mycobiome diversity: high-throughput sequencing and identification of fungi. Nat Rev Microbiol. 2019;17:95-109. https://doi.org/10.1038/ s41579-018-0116-y.

16. Richard ML, Sokol H. The gut mycobiota: insights into analysis, environmental interactions and role in gastrointestinal diseases. Nat Rev Gastroenterol Hepatol. 2019;16:331-45. https://doi.org/10.1038/ s41575-019-0121-2.

17. van Tilburg Bernardes E, Pettersen VK, Gutierrez MW, Laforest-Lapointe I, Jendzjowsky NG, Cavin JB, et al. Intestinal fungi are causally implicated in microbiome assembly and immune development in mice. Nat Commun. 2020. https://doi.org/10.1038/s41467-020-16431-1.

18. Li J, Li L, Jiang H, Yuan L, Zhang L, Ma J, et al. Fecal bacteriome and mycobiome in bats with diverse diets in South China. Curr Microbiol. 2018;75:1352-61. https://doi.org/10.1007/s00284-018-1530-0.

19. Ravenscraft A, Berry M, Hammer T, Peay K, Boggs C. Structure and function of the bacterial and fungal gut microbiota of Neotropical butterflies. Ecol Monogr. 2019;89: e01346. https://doi.org/10.1002/ecm.1346.

20. Barelli C, Albanese D, Stumpf RM, Asangba A, Donati C, Rovero F, et al. The gut microbiota communities of wild arboreal and ground-feeding tropical primates are affected differently by habitat disturbance. mSystems. 2020. https://doi.org/10.1128/msystems.00061-20.

21. Iliev ID, Funari VA, Taylor KD, Nguyen Q, Reyes CN, Strom SP, et al. Interactions between commensal fungi and the C-type lectin receptor dectin-1 influence colitis. Science (80-). 2012;336:1314-7. https://doi.org/10.1126/ SCIENCE.1221789.

22. Auchtung TA, Fofanova TY, Stewart CJ, Nash AK, Wong MC, Gesell JR, et al. Investigating colonization of the healthy adult gastrointestinal tract by fungi. mSphere. 2018. https://doi.org/10.1128/msphere.00092-18.

23. Fiers WD, Gao IH, Iliev ID. Gut mycobiota under scrutiny: fungal symbionts or environmental transients? Curr Opin Microbiol. 2019;50:79-86.

24. Suhr MJ, Hallen-Adams HE. The human gut mycobiome: pitfalls and potentials-a mycologist's perspective. Mycologia. 2015;107:1057-73. https://doi.org/10.3852/15-147.

25. Knight R, Vrbanac A, Taylor BC, Aksenov A, Callewaert C, Debelius J, et al. Best practices for analysing microbiomes. Nat Rev Microbiol. 2018;16:410-22. https://doi.org/10.1038/s41579-018-0029-9.

26. Deiner K, Bik HM, Mächler E, Seymour M, Lacoursière-Roussel A, Altermatt $F$, et al. Environmental DNA metabarcoding: transforming how we survey animal and plant communities. Mol Ecol. 2017;26:5872-95. https://doi. org/10.1111/mec.14350

27. Lavrinienko A, Jernfors T, Koskimäki JJ, Pirttilä AM, Watts PC. Does intraspecific variation in rDNA copy number affect analysis of microbial communities? Trends Microbiol. 2021;29:19-27. https://doi.org/10.1016/j. tim.2020.05.019.

28. Caporaso JG, Lauber CL, Walters WA, Berg-Lyons D, Lozupone CA, Turnbaugh PJ, et al. Global patterns of $16 \mathrm{~S}$ rRNA diversity at a depth of millions of sequences per sample. Proc Natl Acad Sci. 2011;108(Supplement_1):4516-22. https://doi.org/10.1073/pnas.1000080107.

29. Nilsson RH, Larsson KH, Taylor AFS, Bengtsson-Palme J, Jeppesen TS, Schigel $D$, et al. The UNITE database for molecular identification of fungi: handling dark taxa and parallel taxonomic classifications. Nucleic Acids Res. 2019;47:D259-64. https://doi.org/10.1093/nar/gky1022.

30. Hugerth LW, Andersson AF. Analysing microbial community composition through amplicon sequencing: from sampling to hypothesis testing. Front Microbiol. 2017. https://doi.org/10.3389/fmicb.2017.01561.

31. Huseyin CE, Rubio RC, O'Sullivan O, Cotter PD, Scanlan PD. The fungal frontier: a comparative analysis of methods used in the study of the human gut mycobiome. Front Microbiol. 2017. https://doi.org/10.3389/ fmicb.2017.01432.

32. Bolyen E, Rideout JR, Dillon MR, Bokulich NA, Abnet CC, Al-Ghalith GA et al. Reproducible, interactive, scalable and extensible microbiome data science using QIIME 2. Nat Biotechnol. 2019;37:852-7. https://doi.org/10. 1038/s41587-019-0209-9.

33. Bendová B, Piálek J, Ďureje L, Schmiedová L, Čížková D, Martin JF, et al. How being synanthropic affects the gut bacteriome and mycobiome: comparison of two mouse species with contrasting ecologies. BMC Microbiol. 2020;20:1-13. https://doi.org/10.1186/s12866-020-01859-8.

34. Antwis RE, Beresford NA, Jackson JA, Fawkes R, Barnett CL, Potter E, et al. Impacts of radiation exposure on the bacterial and fungal microbiome of small mammals in the Chernobyl Exclusion Zone. J Anim Ecol. 2021. https://doi.org/10.1111/1365-2656.13507.

35. Sawaswong V, Chanchaem P, Khamwut A, Praianantathavorn K, Kemthong T, Malaivijitnond S, et al. Oral-fecal mycobiome in wild and captive cynomolgus macaques (Macaca fascicularis). Fungal Genet Biol. 2020;144: 103468. https://doi.org/10.1016/j.fgb.2020.103468.

36. Siriyappagouder P, Kiron V, Lokesh J, Rajeish M, Kopp M, Fernandes J. The intestinal mycobiota in wild zebrafish comprises mainly dothideomycetes while saccharomycetes predominate in their laboratory-reared counterparts. Front Microbiol. 2018;9:387. https://doi.org/10.3389/fmicb. 2018.00387.

37. Lee C, Tell LA, Hilfer T, Vannette RL. Microbial communities in hummingbird feeders are distinct from floral nectar and influenced by bird visitation. Proc R Soc B Biol Sci. 2019;286:20182295. https://doi.org/10.1098/ rspb.2018.2295.

38. Niemelä T. On Fennoscandian polypores 9. Gelatoporia n. gen. and Tyromyces canadensis, plus notes on Skeletocutis and Antrodia. Karstenia. 1985;25:21-40

39. Mann AE, Mazel F, Lemay MA, Morien E, Billy V, Kowalewski M, et al. Biodiversity of protists and nematodes in the wild nonhuman primate gut. ISME J. 2020;14:609-22. https://doi.org/10.1038/s41396-019-0551-4.

40. Eberl F, de Bobadilla MF, Reichelt M, Hammerbacher A, Gershenzon J, Unsicker SB. Herbivory meets fungivory: insect herbivores feed on plant pathogenic fungi for their own benefit. Ecol Lett. 2020;23:1073-84. https://doi.org/10.1111/ELE.13506.

41. Jiang H, Chen W, Su L, Huang M, Lin L, Su Q, et al. Impact of host intraspecies genetic variation, diet, and age on bacterial and fungal intestinal microbiota in tigers. Microbiologyopen. 2020. https://doi.org/10.1002/ mbo3.1050.

42. Czurda S, Smelik S, Preuner-Stix S, Nogueira F, Lion T. Occurrence of fungal DNA contamination in PCR reagents: approaches to control and decontamination. J Clin Microbiol. 2016;54:148-52. https://doi.org/10. 1128/JCM.02112-15.

43. Preuner $\mathrm{S}$, Lion T. Towards molecular diagnostics of invasive fungal infections. Expert Rev Mol Diagn. 2009;9:397-401. https://doi.org/10.1586/ erm.09.27.

44. Knights D, Kuczynski J, Charlson ES, Zaneveld J, Mozer MC, Collman RG, et al. Bayesian community-wide culture-independent microbial source tracking. Nat Methods. 2011;8:761-5. https://doi.org/10.1038/nmeth. 1650.

45. Višňovska D, Pyszko P, Šigut M, Kostovčik M, Kolařik M, Kotaskova N, et al. Caterpillar gut and host plant phylloplane mycobiomes differ: a new perspective on fungal involvement in insect guts. FEMS Microbiol Ecol. 2020;96:42. https://doi.org/10.1093/femsec/fiaa1 16.

46. Egidi E, Delgado-Baquerizo M, Plett JM, Wang J, Eldridge DJ, Bardgett RD, et al. A few Ascomycota taxa dominate soil fungal communities worldwide. Nat Commun. 2019. https://doi.org/10.1038/s41467-019-10373-z.

47. Větrovský T, Morais D, Kohout P, Lepinay C, Algora C, Awokunle Hollá S, et al. GlobalFungi, a global database of fungal occurrences from highthroughput-sequencing metabarcoding studies. Sci Data. 2020. https:// doi.org/10.1038/s41597-020-0567-7.

48. Risely A. Applying the core microbiome to understand host-microbe systems. J Anim Ecol. 2020. https://doi.org/10.1111/1365-2656.13229.

49. Berg G, Rybakova D, Fischer D, Cernava T, Vergès M-CC, Charles T, et al. Microbiome definition re-visited: old concepts and new challenges. Microbiome. 2020;8:1-22. https://doi.org/10.1186/S40168-020-00875-0.

50. Nash AK, Auchtung TA, Wong MC, Smith DP, Gesell JR, Ross MC, et al. The gut mycobiome of the human microbiome project healthy cohort. Microbiome. 2017;5:153. https://doi.org/10.1186/s40168-017-0373-4.

51. Hallen-Adams HE, Kachman SD, Kim J, Legge RM, Martínez I. Fungi inhabiting the healthy human gastrointestinal tract: a diverse and dynamic community. Fungal Ecol. 2015;15:9-17. https://doi.org/10.1016/j.funeco. 2015.01.006. 
52. Tang J, lliev ID, Brown J, Underhill DM, Funari VA. Mycobiome: approaches to analysis of intestinal fungi. J Immunol Methods. 2015;421:112-21. https://doi.org/10.1016/j.jim.2015.04.004.

53. Rosshart SP, Herz J, Vassallo BG, Hunter A, Wall MK, Badger JH, et al. Laboratory mice born to wild mice have natural microbiota and model human immune responses. Science (80-). 2019;365:eaaw4361. https://doi.org/10. 1126/science.aaw4361.

54. Nguyen NH, Song Z, Bates ST, Branco S, Tedersoo L, Menke J, et al. FUNGuild: an open annotation tool for parsing fungal community datasets by ecological guild. Fungal Ecol. 2016;20:241-8. https://doi.org/10.1016/j. funeco.2015.06.006

55. Zanne AE, Abarenkov K, Afkhami ME, Aguilar-Trigueros CA, Bates S, Bhatnagar JM, et al. Fungal functional ecology: bringing a trait-based approach to plant-associated fungi. Biol Rev. 2020;95:409-33. https://doi. org/10.1111/BRV.12570

56. Pölme S, Abarenkov K, Henrik Nilsson R, Lindahl BD, Clemmensen KE, Kauserud $\mathrm{H}$, et al. FungalTraits: a user-friendly traits database of fungi and fungus-like stramenopiles. Fungal Divers. 2021;105:1-16. https://doi.org/ 10.1007/S13225-020-00466-2.

57. Eloe-Fadrosh EA, Brady A, Crabtree J, Drabek EF, Ma B, Mahurkar A, et al. Functional dynamics of the gut microbiome in elderly people during probiotic consumption. MBio. 2015. https://doi.org/10.1128/MBIO.00231-15.

58. Di Rienzi SC, Sharon I, Wrighton KC, Koren O, Hug LA, Thomas BC, et al. The human gut and groundwater harbor non-photosynthetic bacteria belonging to a new candidate phylum sibling to Cyanobacteria. Elife. 2013. https://doi.org/10.7554/eLife.01102.
59. Fisher MC, Gurr SJ, Cuomo CA, Blehert DS, Jin H, Stukenbrock EH, et al. Threats posed by the fungal kingdom to humans, wildlife, and agriculture. MBio. 2020;11:449-69. https://doi.org/10.1128/mBio.00449-20.

60. Martin M. Cutadapt removes adapter sequences from high-throughput sequencing reads. EMBnet.journal. 2011;17:10. doi:https://doi.org/10. 14806/ej.17.1.200.

61. Callahan BJ, McMurdie PJ, Rosen MJ, Han AW, Johnson AJA, Holmes SP. DADA2: high-resolution sample inference from Illumina amplicon data. Nat Methods. 2016;13:581-3. https://doi.org/10.1038/nmeth.3869.

62. Rognes T, Flouri T, Nichols B, Quince C, Mahé F. VSEARCH: a versatile open source tool for metagenomics. PeerJ. 2016;4: e2584. https://doi.org/10. 7717/PEERJ.2584

63. McMurdie PJ, Holmes S. phyloseq: an R package for reproducible interactive analysis and graphics of microbiome census data. PLoS ONE. 2013;8: e61217. https://doi.org/10.1371/journal.pone.0061217.

64. Oksanen J, Blanchet FG, Friendly M, Kindt R, Legendre P, McGlinn D, et al. vegan: community ecology package. R package version 2.5-6. https:// CRANR-project.org/package=vegan. 2019. https://cran.r-project.org/ web/packages/vegan/index.html. Accessed 22 Apr 2020.

\section{Publisher's Note}

Springer Nature remains neutral with regard to jurisdictional claims in published maps and institutional affiliations.
Ready to submit your research? Choose BMC and benefit from:

- fast, convenient online submission

- thorough peer review by experienced researchers in your field

- rapid publication on acceptance

- support for research data, including large and complex data types

- gold Open Access which fosters wider collaboration and increased citations

- maximum visibility for your research: over 100M website views per year

At BMC, research is always in progress.

Learn more biomedcentral.com/submissions 